\title{
Letter from the Editors
}

7 esearch in the field of Living Systems is unthinkable without international cooperation. One of the impor1 tant sections in our journal is now devoted to reviews penned by leading domestic and foreign scientists. These authors represent the leading scientific schools of Russia, Europe, and the U.S..

In addition, we publish the results of work conducted by international research groups in the experimental section of our journal. Hence, this issue contains an article written in collaboration with our Japanese colleagues that focuses on the study of the enzyme deacylation process for the family of penicillin-binding proteins. Another experimental paper written by a team of German scientists highlights the possibility of using $2 \mathrm{D}$-gel electrophoresis to study a receptor complex.

Some of the materials in the section "Forum" are devoted to an important aspect of international cooperation in the field of Living Systems: the article is about customs tariffs as barriers to the development of biotechnology and possible ways to overcome them.

Taking further the topic of state support of science initiated in the previous issue (Acta Naturae, 2010, Volume 2, № 1 (4)), we are offering material on the implementation of the Federal Target Program Research and Scientific-Pedagogical Human Resources.

We are also exited to share with our readers some good news: the journal Acta Naturae has been entered into the list of the leading periodicals of the Higher Attestation Commission of the Russian Ministry of Education and Science. We hope this distinction will steer more and more young researchers in our direction.

\section{Editorial Board}

